\title{
May the extraction of fresh thrombus prevent no-reflow phenomenon in coronary artery bypass surgery?
}

\author{
Ertan Demirdaş ${ }^{1}$, Kıvanç Atılgan $^{1}$, Ferit Çiçekçioğlu ${ }^{1}$
}

1) Bozok University Research and Application Hospital and Cardiovascular Surgery, Assist. Prof., Yozgat, Turkey

\begin{abstract}
The most frequent reason of acute coronary syndrome is the occlusion of coronary artery with thrombus due to the rupture of the plaque in it. Treatment involves medical treatment, percutaneous coronary interventions and coronary artery bypass grafting (CABG). In CABG the revascularization of the coronary artery and, if necessary, the extraction of thrombus may be lifesaving.
\end{abstract}

Keywords: Thrombus, acute coronary yndrome, coronary artery bypass 


\section{Introduction}

The most frequent reason for the acute coronary syndrome (ACS) is the occlusion of the coronary artery with the thrombus due to the rupture of the plaque in the coronary artery. ${ }^{(1)}$ The cure involves medical treatment, percutaneous coronary inteventions (PCI) and coronary artery bypass grafting $(\mathrm{CABG}) .^{(2-4)}$ Concisely, medical treatments are anti-ischaemic, anti-thrombotic and fibrinolytic treatments. PCI has a very important position in ACS as a well accepted and spreading process. PCI enables both the stabilization of the ruptured plaque and the resolution of the thrombus in the coronary artery. Revascularization of the totally occluded coronary artery due to the rupture of a plaque and the extraction of the thrombus, during CABG being performed under emergent circumstances, provides us to have pleasing results in morbidity and mortality.

\section{Case History}

A 37-year old male without a history of an accompanying illness or drug utilization was referred to our clinic with a severe chest pain. Having the results of inferior ST elevations in the electrocardiogram and troponin I:21 $\mathrm{ng} / \mathrm{ml}$ in biochemical tests, $600 \mathrm{mg}$ of Clopidogrel per orally and 10000 Units of Enoxaparine subcutaneously

Figure 1. Fresh thrombus is seen after coronary incision

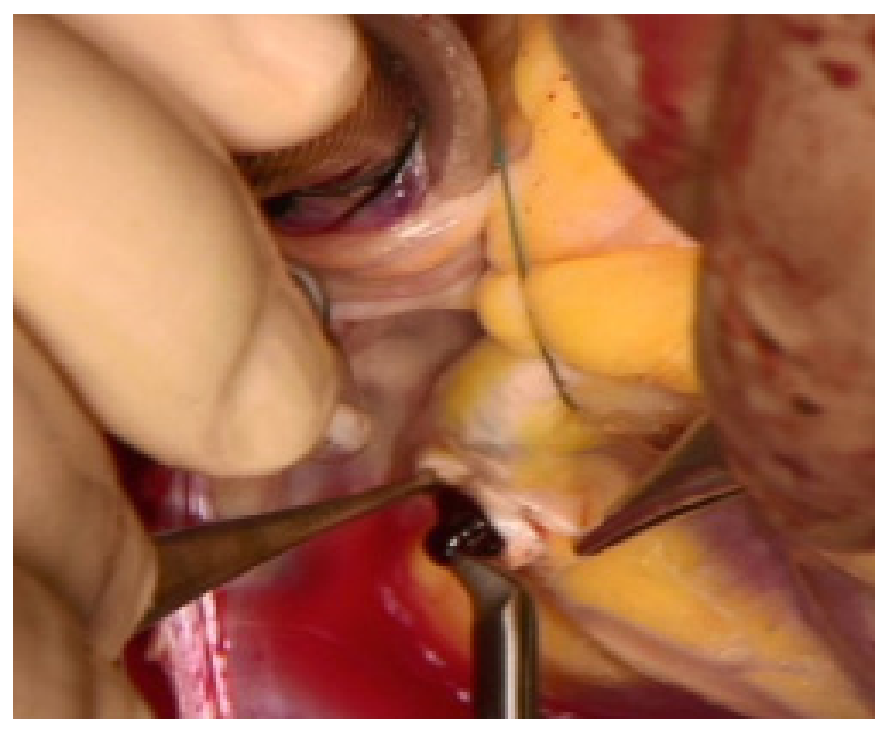

were applied to the patient. Three vessel disease and a filling defect in the right coronary artery compatible with thrombus were observed in coronary angiography. The patient with unstabil angina underwent an emergent CABG on the fourth hour of chest pain.

\section{Operating Procedure}

The patient was operated under emergent circumstances. Following median sternotomy, saphenous vein grafts and left internal mammarian arteries (LIMA) were harvested. After having cardiac arrest with ategrade and retrograde cold crystalloid cardioplegia, arteriotomy was applied on the distal body of the right coronary artery, just before the bifurcation of the posterior descending artery and the posterolateral artery.

We observed a fresh thrombus and a thrombectomy process was applied with a $2 \mathrm{~F}$ Fogarty catheter (Figure 1, 2). Then, right coronary arter bypass was applied with the saphenous vein graft. LIMA was anastomosed to the left anterior descending artey and the other part of the saphenous vein graft was anastomosed to the optional diagonal and optus marginalis arteries sequatially. After decannulation and the neutralization of heparin with prothrombin, tranexamic acid was infused with a dose of $15 \mathrm{mg} / \mathrm{kg}$. The patient

\section{Figure 2. The embolectomy of fresh thrombus}

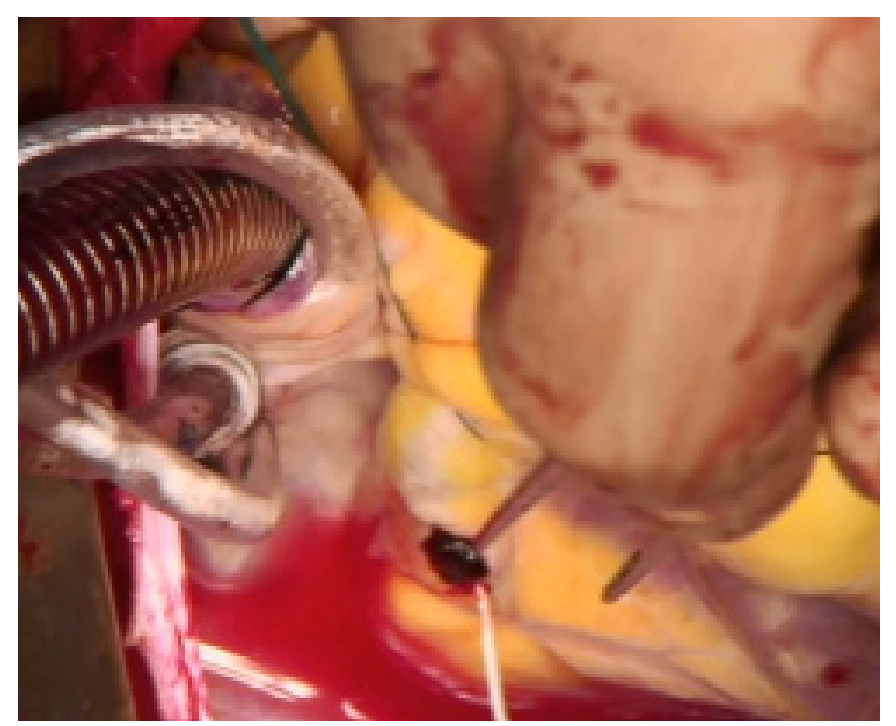


was discharged on the postoperative fourth day.

\section{Discussion}

Soft plaques are pathologies with a high risk of rupture resulting with the acute occlusion of the coronary artery and, hence, ACS compeling the patient to face serious fatal complications. Thus, ACS has an important place among the corornary artery diseases. Despite the early diagnosis and the provision of TIMI 3 flow after the revascularization with even $\mathrm{CABG}$ or PCI, sometimes, it may be possible to observe the persistence of the myocardial ischaemia.

It is not uncommon having unsufficient myocardial response, haemodynamic instability resulting with the initiation of positive inotropic drug and intraaortic ballon pump treatments despite the succesfull coronary artery bypassing and effective heart protecting techniques. This situation is called as "No-relow phenomenon", which is a conclusion of multiple factors as microvascular spasm, thrombus load, endothelial dysfunction, inflammatory neutrophil activation, interstitial edema and embolization..$^{(5-7)}$

The distal embolization of the microparticulas of fresh thrombus in the coronary artery having a soft plaque anatomy is the main point of the pathophysiology in this process. The mortality rate has a ten fold increase in the patients having no-reflow phenomenon in comparison with the ones not having noreflow phenomenon. ${ }^{(8-10)}$ Thus, in this case we prefered to extract the fresh thrombus in the coronary artery.

As a result, we believe that among the patients undergoing emergent $\mathrm{CABG}$ due to ACS inflicting because of the acute rupture of soft palque and total occlusion of the artery with fresh thrombus, bypassing the coronary arteries after the extraction of the fresh thrombus would save better mortality and morbidity rates and survey. 


\section{References}

1. Mackman N. Triggers, targets and treatments for thrombosis. Nature $2008 ; 451: 914-8$.

2. Overbaugh KJ. Acute coronary syndrome. Am J Nurs 2009;109:42-52.

3. Hamm CW, Bassand JP, Agewall S et al. ESC Guidelines for the management of acute coronary syndromes in patients presenting without persistent ST-segment elevation: The Task Force for the Management of Acute Coronary Syndromes (ACS) in Patients Presenting without Persistent ST-segment Elevation of the European Society of Cardiology (ESC). Eur Heart J 2011;32:2999-3054.

4. Van de Werf F, Bax J, Betriu A et al. ESC Guidelines for the management of acute myocardial infarction in patients presenting with ST-segment elevation: the Task Force on the Management of ST-segment Elevation Acute Myocardial Infarction of the European Society of Cardiology. Eur Heart J 2012;33:2569-619.

5. Shereif Rezkalla, Robert A. Kloner. No-reflow phenomenon: current perspective. Circulation. 2002;105:656-662.
6. Manciet LH, Poole DC, McDonagh PF, et al. Microvascular compression during myocardial ischemia: mechanistic basis for noreflow phenomenon. Am J Physiol 1994;266:H1541-50:SLEP

7. Yip HK, Chen MC, Chang HW, Hang CL, Hsieh YK, Fang CY Wu CJ. Angiographic morphologic features of infarct-related arteries and timely reperfusion in acute myocardial infarction: predictors of slow-flow and no-reflow phenomenon. Chest 2002; 122(4): 1322-1332. 81. Schroder R: ST segment resolution on 12-lead ECG. Circulation 2004

8. Kitazume H, Iwama T, Kubo H, et al. No-reflow phenomenon during percutaneous transluminal coronary angioplasty. Am Heart J 1988;116:211-5.

9. Piana RN, Paik GY, Moscucci M, et al. Incidence and treatment of no-reflow after percutaneous coronary intervention. Circulation 1994;89:2514-8.

10. Abbo KM, Dooris M, Glazier S, et al. No-reflow after percutaneous coronary intervention: Clinical and angiographic characteristics, treatment and outcome. Am J Cardiol 1995;75:778-82.

Received: 15/03/2016

Accepted: 22/05/2016

Published: 20/06/2016

Disclosure and conflicts of interest:

Conflicts of interest were not reported.

\section{Corresponding author:}

Dr. Kıvanç Atılgan

Mail: kivancatilgan@gmail.com 